\title{
Investigating the Role of Ocean-Atmosphere Coupling in the North Pacific Ocean
}

\author{
DimitRY SMIRNOV AND MATTHEW NEWMAN \\ CIRES, University of Colorado at Boulder, and NOAA/Earth System Research Laboratory, Boulder, Colorado \\ Michael A. AlexAnder \\ NOAA/Earth System Research Laboratory, Boulder, Colorado
}

(Manuscript received 19 February 2013, in final form 25 August 2013)

\begin{abstract}
Air-sea interaction over the North Pacific is diagnosed using a simple, local coupled autoregressive model constructed from observed 7-day running-mean sea surface temperature (SST) and 2-m air temperature $T_{A}$ anomalies during the extended winter from the $1^{\circ} \times 1^{\circ}$ objectively analyzed air-sea fluxes (OAFlux) dataset. Though the model is constructed from 1-week lag statistics, it successfully reproduces the observed anomaly evolution through lead times of 90 days, allowing an estimation of the relative roles of coupling and internal atmospheric and oceanic forcing upon North Pacific SSTs. It is found that east of the date line, SST variability is maintained by, but has little effect on, $T_{A}$ variability. However, in the Kuroshio-Oyashio confluence and extension region, about half of the SST variability is independent of $T_{A}$, driven instead by SST noise forcing internal to the ocean. Including surface zonal winds in the analysis does not alter this conclusion, suggesting $T_{A}$ adequately represents the atmosphere. Repeating the analysis with the output of two control simulations from a fully coupled global climate model (GCM) differing only in their ocean resolution yields qualitatively similar results. However, for the simulation employing the coarse-resolution $\left(1^{\circ}\right)$ ocean model, all SST variability depends upon $T_{A}$, apparently caused by a near absence of ocean-induced noise forcing. Collectively, these results imply that a strong contribution from internal oceanic forcing drives SST variability in the Kuroshio-Oyashio region, which may be used as a justification for atmospheric GCM experiments forced with SST anomalies in that region alone. This conclusion is unaffected by increasing the dimensionality of the model to allow for intrabasin interaction.
\end{abstract}

\section{Introduction}

The importance of air-sea interaction to extratropical atmospheric variability has been the subject of research for over 50 years (Namias 1959; Bjerknes 1964). The fundamental issue is that while sea surface temperature (SST) anomalies are largely forced by the atmosphere (Cayan 1992), they can feed back onto the atmosphere (Kushnir et al. 2002). This coupled system was expressed simply by Barsugli and Battisti (1998, hereafter BB98), as

$\frac{d}{d t}\left[\begin{array}{l}T_{A} \\ T_{S}\end{array}\right]=\left[\begin{array}{ll}a & b \\ c & d\end{array}\right]\left[\begin{array}{c}T_{A} \\ T_{S}\end{array}\right]+\left[\begin{array}{c}\xi_{A} \\ 0\end{array}\right] \begin{aligned} & b: T_{S} \rightarrow T_{A} \\ & c: T_{A} \rightarrow T_{S}\end{aligned}$

where $T_{S}$ and $T_{A}$ are anomalous SST and surface air temperature, respectively, and $\xi_{A}$ represents the random

Corresponding author address: Dimitry Smirnov, NOAA/ESRL, 325 Broadway, R/PSD1, Boulder, CO 80305.

E-mail: dima.smirnov@noaa.gov atmospheric forcing (e.g., synoptic weather variability) that exists regardless of SST variability. The diagonal coefficients $a$ and $d$ represent the intrinsic damping of $T_{A}$ and $T_{S}$, respectively, while the off-diagonal elements $b$ and $c$ quantify the coupling: $b$ is the effect of $T_{S} \rightarrow T_{A}$, vice versa for $c$. Equation (1) can be considered a null hypothesis for air-sea coupling and an extension to the simpler null hypothesis of atmospheric forcing of the uncoupled ocean (Frankignoul and Hasselmann 1977, hereafter FH77). Notably, this hypothesis implies that internal oceanic variability is not important in forcing $T_{S}$ anomalies.

BB98 suggested that coupling increases the persistence of SST anomalies by about $50 \%$ through "reduced thermal damping"; that is, as $T_{A}$ adjusts to the underlying SST at longer time scales, the heat flux between the two (in a system driven purely by $T_{A}$ ) tends to approach zero. Consequently, running long-duration atmospheric global climate models (GCMs) forced in the extratropics by observed historical SST anomalies is problematic 
because of a large, potentially spurious upward surface heat flux (latent + sensible; upward being from the ocean to the atmosphere) at low frequencies (BB98; Saravanan 1998; Bretherton and Battisti 2000; Sutton and Mathieu 2002). In addition, previous large-scale SST-forced AGCM experiments (e.g., Peng et al. 1995, 1997; Kushnir and Held 1996; Kushnir et al. 2002) have not, in general, tended to support a significant role for extratropical SST forcing of the atmosphere. This is in stark contrast to the well-documented role of tropical SST anomalies in remotely generating extratropical atmospheric and SST anomalies (e.g., Ferranti et al. 1994; Alexander et al. 2002; Hoerling and Kumar 2002).

The assumption made by FH77 and BB98 is that SSTs are driven purely by random atmospheric variability. However, in the vicinity of western boundary currents (WBCs), SST variability is not simply a passive response to surface heat flux forcing (Frankignoul and Reynolds 1983), but instead may be forced by ocean dynamics and transport (Kelly 2004). For example, westward oceanic Rossby wave propagation resulting from anomalous wind stress curl forcing in the central and eastern Pacific (Deser et al. 1999; Schneider et al. 2002) can result in anomalous heat transport within the Kuroshio that is of the same order of magnitude as the surface heat flux, often changing the sign of the SST tendency implied from the surface heat flux alone (Qiu 2000). Ekman advection, especially in the vicinity of SST fronts, can also be an important factor in driving SST changes as shown for the North Pacific by Miller et al. (1994). In fact, Lee et al. (2008) extended the BB98 model through the inclusion of SST noise (as a function of atmospheric noise) and found that this could substantially mitigate the impact of reduced thermal damping. Dong and Kelly (2004) suggest that Ekman advection plays a secondary role to geostrophic currents in forcing mixed-layer temperature changes within the upper 400-m layer of the Gulf Stream, although since $400 \mathrm{~m}$ is substantially deeper than the Ekman layer, they may have underestimated the direct role of Ekman currents on SST.

Additionally, Nakamura et al. (2004) showed that the most active regions of synoptic atmospheric eddies are strongly collocated with WBCs and their associated SST fronts, creating intense upward surface heat fluxes. However, whether this collocation is caused by the strong SST gradient (Minobe et al. 2008) or from the land-sea thermal contrast (Brayshaw et al. 2009, 2011) is still an open question. Regardless, the rapid $T_{A}$ damping time scales (up to 1 day $^{-1}$; Nonaka et al. 2009) over the SST gradient can be expected to be partially due to the differential sensible heat flux forcing maintained by the SST front (Nakamura et al. 2008; Taguchi et al. 2009). In short, there is evidence that air-sea interaction may exhibit differences within the western portions of extratropical oceans compared to the east because of the elevated role of internal oceanic thermal processes.

The purpose of this study is to examine how air-sea interaction differs across the extratropical North Pacific. We construct an empirical version of the local, coupled model of BB98 using (1) with the relatively new objectively analyzed air-sea fluxes (OAFlux) observational dataset (Yu and Weller 2007). Unlike BB98, however, we allow for the possibility of both $T_{A}$ and $T_{S}$ stochastic forcing. There are several questions we seek to answer. Is the local, coupled model equally valid across different portions of the North Pacific? If not, can the model be improved by allowing for nonlocal interaction? Does the role of coupling have a geographical dependence? How significant is the omission of oceanic noise in BB98's model? And finally, how well do coupled GCMs capture midlatitude air-sea interaction within our framework?

The manuscript is ordered in the following manner. In section 2, we describe the observational and coupled GCM datasets and how the empirical model is constructed. Section 3 contains the main results, including the spatial structure of the coupled model coefficients, and an evaluation of how well the model reproduces observed statistics and how coupling varies across the basin. Also in section 3 is a comparison of how the empirical model performs when applied to the output of a coupled GCM. In section 4, we consider the role of remote forcing and whether it changes the interpretation of the local model. Finally, conclusions are provided in section 5, along with open questions stemming from this study.

\section{Constructing the local, coupled model}

\section{a. Observations}

In contrast to BB98, we develop the local, coupled model empirically using linear inverse modeling (LIM; Penland 1989; Mosedale et al. 2005). In this case, the LIM portrays a bivariate Markov process that is forced by Gaussian white noise $\xi$ :

$$
\frac{d \mathbf{x}}{d t}=\mathbf{L x}+\xi
$$

where the state vector $\mathbf{x}(t)=\left[T_{A}(t) T_{S}(t)\right]^{\mathrm{T}}$ represents the time evolution of 7-day running-mean anomalies of 2-m air temperature $T_{A}$ and SST $T_{S}$ taken from the $1^{\circ} \times$ $1^{\circ}$ OAFlux dataset ( $\mathrm{Yu}$ and Weller 2007) from 1985 to 2009. Note that in contrast to BB98, $\xi$ includes both $T_{A}$ and $T_{S}$ noise forcing (Zubarev and Demchenko $1992)$. We focus on the North Pacific $\left(20^{\circ}-60^{\circ} \mathrm{N}, 120^{\circ} \mathrm{E}-\right.$ $\left.120^{\circ} \mathrm{W}\right)$ during the extended boreal winter months 
[November-March (NDJFM)], which reduces the role of reemergence on $T_{S}$ anomalies (Alexander and Deser 1995). Repeating the analysis on the winter-only period (December-February) yields very consistent results. To avoid the impact of sea ice, all grid points where the minimum SST is below $-1.8^{\circ} \mathrm{C}$ are excluded. The term $\mathbf{L}$ is the feedback, or deterministic, matrix of similar coefficients as in BB98:

$$
\mathbf{L}=\left[\begin{array}{ll}
a & b \\
c & d
\end{array}\right] .
$$

The determination of $\mathbf{L}$ and other details regarding the LIM can be found in the appendix. Briefly, a LIM is fit to each point [by finding $\mathbf{L}$ using the lagged covariance of $\mathbf{x}$ via (A1) and the noise covariance $\mathbf{Q}=\left\langle\xi \xi^{\mathrm{T}}\right\rangle d t$ as a residual in the fluctuation-dissipation relation via (A3)]; collectively, we refer to the one-dimensional (bivariate) model as the local LIM. Note that we term an "uncoupled" system as one where $b$ and $c=0$. In contrast, BB98 refer to uncoupled where only $b=0$ since their aim was to contrast a system with a slave ocean to that with prescribed SST (setting $b$ and $c=0$ in BB98 would result in no SST variability). Since we do not assume a passive ocean, but instead use observations to determine the amount of oceanic influence through $\mathbf{Q}$, we are able to also set $c=0$ to determine the intrinsic role of the ocean.

There are several methods to assess the performance of the LIM. One approach is to determine cross-validated forecast skill where starting with $\mathbf{x}(t)$ one can make predictions at various lead times via (A2) and compare to the observed evolution (Winkler et al. 2001; Newman et al. 2003; Kossin and Vimont 2007; Pegion and Sardeshmukh 2011). Because the local LIM has skill comparable to that of the FH77 $T_{S}$-only model (not shown), its value is predominantly of a diagnostic nature. Instead of assessing forecast skill, we compare the predicted covariance [diagonal elements of $\mathbf{C}(0)$ and C $(\tau)$; see the appendix] and cross covariance (offdiagonal elements) to observations as a function of lead time. Nonetheless, we later present skill when comparing the local LIM with a higher-order LIM that allows for remote interaction (section 4). Finally, while the focus here is mainly on seasonal variability, one must remember that the LIM provides a red noise null hypothesis on all time scales.

\section{b. Coupled GCMs}

Recently, it has been recognized that coarse-resolution coupled models generally underestimate smaller-scale oceanic features such as mesoscale eddies and midlatitude SST fronts (Small et al. 2008). For example, Bryan et al.
(2010) showed that the ocean component of a coupled GCM must be eddy resolving in order to reproduce the magnitude of the observed positive correlation between small-scale wind stress and SST anomalies found in earlier studies (e.g., Chelton et al. 2004; Xie 2004). To investigate air-sea interaction within coupled models, we extend the LIM analysis to two simulations of the Community Climate System Model, version 3.5 (CCSM3.5), developed by the National Center for Atmospheric Research (NCAR) (Gent et al. 2010). The simulations only differ in their ocean model, which has a resolution of $0.1^{\circ}\left(1^{\circ}\right)$ in the high-resolution (low resolution) simulation. Details of these simulations are available in Kirtman et al. (2012) (also Bryan et al. 2010) and hereafter we refer to the high-resolution (low resolution) simulations as HR (LR). To maintain consistency with the OAFlux-based local LIM, the output of both GCMs is linearly interpolated to the OAFlux $1^{\circ} \times$ $1^{\circ}$ grid and 25 years of data are sought. However, only 19 years of data are available for the LR simulation. Because a shorter record could affect the fit of $\mathbf{L}$ in (A2), we accessed 30 years of an additional $1^{\circ}$ simulation from the slightly later CCSM, version 4 (Gent et al. 2011; C. Hannay 2012, personal communication). Aside from small differences in the mean climate (e.g., position of WBCs), the LIM coefficients and coupling characteristics of both low-resolution simulations appear very comparable and only LR is discussed hereafter.

\section{Results}

\section{a. Observed and predicted covariance}

Figure 1 shows the wintertime standard deviation $\sigma$ of weekly averaged $T_{S}$ anomalies $\left(\sigma_{S} ;\right.$ Fig. 1a) and weekly and daily averaged $T_{A}$ anomalies $\left(\sigma_{A}\right.$; Figs. $1 \mathrm{~b}, \mathrm{c}$, respectively). Because of the ocean's large thermal inertia, computing $\sigma_{S}$ by averaging $T_{S}$ over increasing time scales (from daily to weekly and weekly to monthly) has a negligible influence on variance (not shown). Enhanced $T_{S}$ variability is found within the KuroshioOyashio confluence and separation region immediately east of Japan (Mitsudera et al. 2004); their extensions near $40^{\circ} \mathrm{N}, 170^{\circ} \mathrm{E}$ (Kwon et al. 2010); and a broad region from $30^{\circ} \mathrm{N}, 180^{\circ}$ northeastward to $40^{\circ} \mathrm{N}, 150^{\circ} \mathrm{W}$ associated with subtropical front variability (Nakamura et al. 1997) and ENSO teleconnections (Alexander 1992; Diaz et al. 2001). In contrast to $T_{S}$, and because of the presence of short-lived synoptic eddies, $\sigma_{A}$ is reduced on average by $30 \%$ after taking weekly averages (cf. Figs. 1b,c, note different color scales). However, the reduction is nonuniform as $\sigma_{A}$ is reduced by $50 \%$ east of Japan but only by $10 \%-20 \%$ in the northeastern Pacific. 
a)Weekly $\sigma_{\mathrm{S}}$
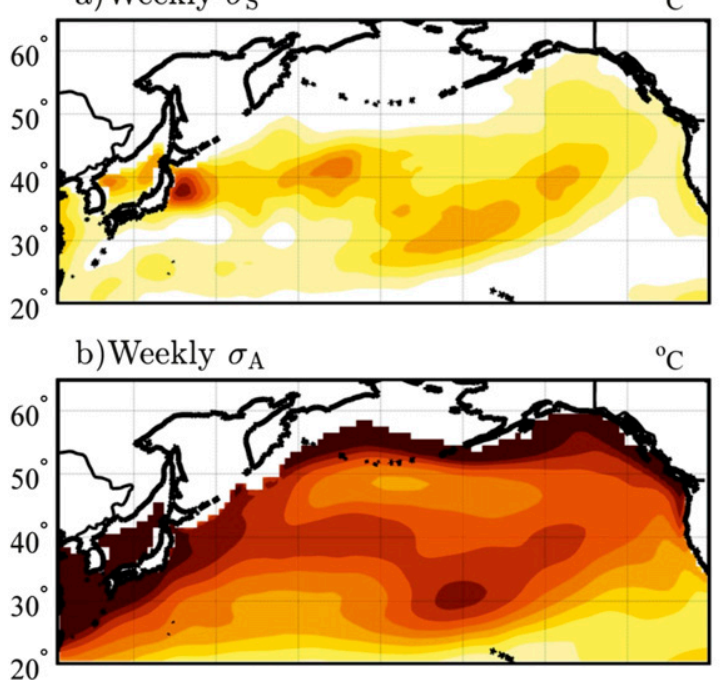

c)Daily $\sigma_{\mathrm{A}}$

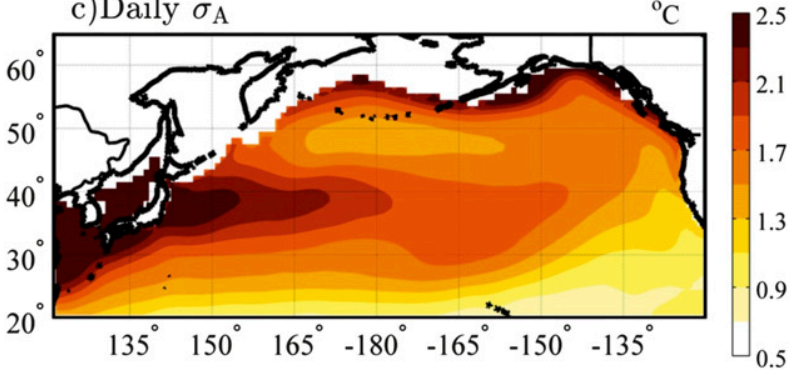

FIG. 1. Standard deviation of (a) weekly averaged $T_{S}$ and (b) weekly and (c) daily averaged $T_{A}$ anomalies from OAFlux, extended winter only (NDJFM). The $T_{S}$ variability is essentially unchanged when averaging daily to weekly to monthly. Weekly average $T_{A}$ is shown because a 7-day running mean is used in the LIM.

Thus, our use of 7-day running-mean anomalies implies that a modest portion of variability is lost in the most active part of the North Pacific storm track. However, the 7-day running mean provides a good compromise between retaining variability and maintaining accurate predictions of lag covariance (see the appendix).

The spatial variability of the $\mathbf{L}$ coefficients is shown in Figs. 2a-d. A Monte Carlo test using synthetically generated data (see section $3 \mathrm{~b}$ for details) suggests that the standard error for coefficients $a, c$, and $d$ is approximately $10 \%$, while that of $b$ is approximately $20 \%$ [likely as a result of the shortness of the record; see Mosedale et al. (2005)]. For reference, the coefficients obtained by BB98 $(a, b, c$, and $d$ are $-0.22,0.10,0.01$, and -0.01 , respectively) would be most representative of a point in the Gulf of Alaska. Diagonal coefficients $a$ and $d$ are damping time scales $\left(\right.$ day $\left.^{-1}\right)$, while off-diagonal coefficients $b$ and $c$ represent coupling strength $\left(b: T_{S} \rightarrow\right.$ $T_{A}$ and $\left.c: T_{A} \rightarrow T_{S}\right)$. Coefficients $a$ and $d$ are negative everywhere, as expected resulting from the damping of SST and $T_{A}$ to climatology through radiative and surface heat flux anomalies (BB98; Frankignoul and Kestenare 2002; Park et al. 2005), regardless of coupling. Note that the $T_{S}$ damping rate $d$ varies by a factor of 3 across the North Pacific, with the smallest values of $|d|$ (i.e., greatest persistence) occurring in regions of strong currents and/or large mixed-layer (ML) depths extending from Japan northeast into the central North Pacific (Alexander 2010). Meanwhile, the highest values of $|d|$ (greatest damping) occur in the subtropical regions of shallow ML depths, where even weak atmospheric forcing can quickly modify SST through surface fluxes and wind-forced entrainment of sub-ML water (Frankignoul 1985; Alexander et al. 2000). Note that this mechanism may also explain the large values of the coupling coefficients in the subtropical region. Conversely, values of the off-diagonal elements are everywhere positive, consistent with reduced thermal damping of both $T_{S}$ and $T_{A}$ (BB98). We can compare our $T_{S}$ feedback strength $b$ to previous midlatitude heat flux feedback estimates of $20-30 \mathrm{~W} \mathrm{~m}^{-2}{ }^{\circ} \mathrm{C}^{-1}$ (e.g., Frankignoul and Kestenare 2002; Park et al. 2005) by converting $b$ into an energy flux that acts on an atmospheric slab of thickness $H_{a}$, density $\rho_{a}$, and heat capacity $C_{a}$. Even when using an 800 -mb thick slab $\left(H_{a} \approx 12000 \mathrm{~m}\right.$; i.e., supposing the feedback acts on the entire troposphere), $\bar{\rho}_{a}=0.80 \mathrm{~kg} \mathrm{~m}^{-3}$, $C_{a}=1000 \mathrm{~J} \mathrm{~kg}^{-1}{ }^{\circ} \mathrm{C}^{-1}$, and the median value of $b=0.11$ $\left(T_{A} T_{S}^{-1}\right.$ day $\left.^{-1}\right)$, we estimate a feedback strength $\alpha=b \bar{\rho}_{a}$ $C_{a} H_{a}$ of $12 \mathrm{~W} \mathrm{~m}^{-2}$, which is lower than previous estimates. The discrepancy signals that previous estimates may have convolved the forcing and feedback, though our estimate may be conservative since we do not explicitly account for wind, moisture, and stability anomalies.

The usefulness of any model is gauged by its ability to reproduce observations. Figure 3 shows the observed lag covariance $\mathbf{C}(\tau)$ for $T_{S}$ and $T_{A}$, with $\tau=(30,60$, and 90 days) representing the degree of persistence over the course of those periods. Regions of high $T_{S}$ persistence coincide with regions of high $T_{S}$ variability (cf. Figs. 3a,c,e with Fig. 1a) consistent with the dominance of slow processes in the ocean. The $T_{A}$ persistence generally resembles that of $T_{S}$ east but not west of the date line (most notably differing in the WBC region), implying either weaker or nonlocal coupling there as may be expected because of the rapid $T_{A}$ variability. Figure 3 also shows where the difference between $\mathbf{C}(\tau)$ and predicted covariance $\widetilde{\mathbf{C}}(\tau)$ significantly differs at the $p=0.025$ level (based on 200 iterations of a Monte Carlo test where $\mathbf{x}$ is subsampled with replacement during the extended winter months). For $\tau=30$ days, the LIM predicts $\widetilde{\mathbf{C}}(\tau)$ very well; as lead time increases (Figs. 3c-f), the LIM continues to do well west of the date line but somewhat underestimates 

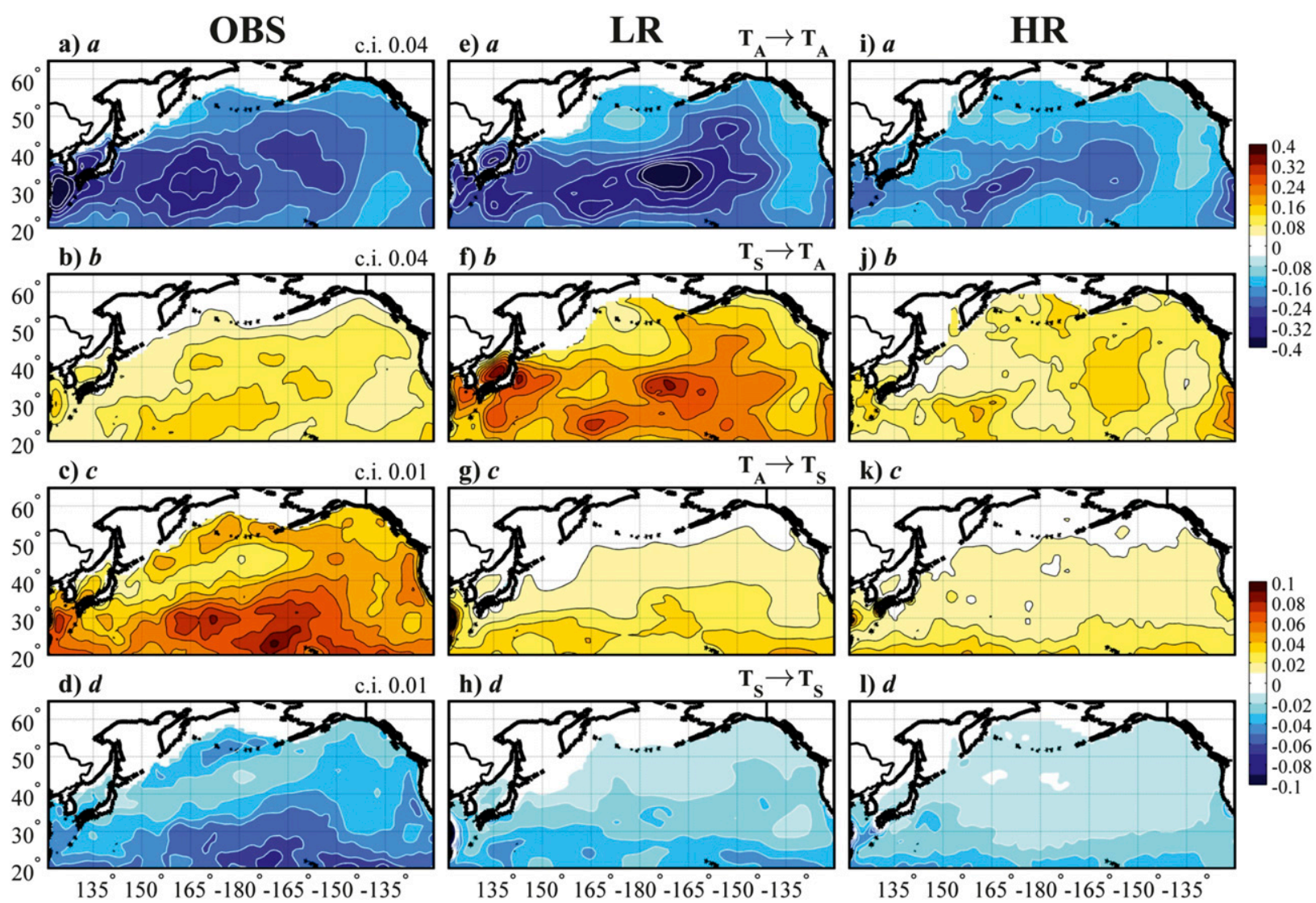

FIG. 2. Spatial variability of the coefficients in the dynamical operator $\mathbf{L}$, found separately for every grid point using (a)-(d) OAFlux observations and (e)-(h) LR and (i)-(l) HR model output. See section 3c for the details of the model configurations. The top (bottom) colorbar corresponds to the top (bottom) two rows. Coefficients $a$ and $d$ represent damping rate (day ${ }^{-1}$ ) of $T_{A}\left(T_{S}\right.$ ), while coefficients $b$ and $c$ represent coupling strength $\left(b: T_{S} \rightarrow T_{A}\right.$ and $\left.c: T_{A} \rightarrow T_{S}\right)$.

SST persistence east of the date line, perhaps because remote ENSO forcing (e.g., Alexander et al. 2002) is not fully captured by the local LIM. For long lags, an additional complication is a changing mixed-layer depth, which will clearly affect the coefficients in $\mathbf{L}$. Meanwhile, Figs. $3 \mathrm{~b}, 3 \mathrm{~d}$, and $3 \mathrm{e}$ show that $\widetilde{\mathbf{C}}(\tau)$ for $T_{A}$ displays similar characteristics as $T_{S}$, although persistent $T_{A}$ variability is limited to east of the date line. The predicted lag cross covariance [i.e., off-diagonal elements of $\widetilde{\mathbf{C}}(\tau)$ when $T_{S}$ either leads or lags $T_{A}$ ] shows very similar characteristics as Fig. 3 and is discussed further in section 4 .

The local LIM predicts $\widetilde{\mathbf{C}}(\tau)$ for $T_{S}$ in the WBC region remarkably well despite the concern of previous studies when using the FH77-type model in a dynamically active ocean region (Reynolds 1978; Hall and Manabe 1997). The chief issue is how the local LIM treats oceanic processes, which are either represented deterministically in the $T_{S}$ damping coefficient $d$ or are captured by $T_{S}$ noise forcing. Since the LIM is trained using a 7-day lag, it is possible that $d$ also implicitly includes the effect of anomalous currents and perhaps the aggregate effect of mixing by eddies. This can be further investigated by both increasing the training lag (though with the expense of smoothing the data) and incorporating other variables such as sea surface height anomalies, but we leave this matter for future research. Frankignoul and Reynolds (1983) extended the FH77 model to include an estimate of the mean current acting on anomalous $\nabla T_{S}$, finding only a slightly increased $T_{S}$ persistence time on seasonal time scales. However, they were not able to estimate the role of anomalous currents and their use of EOF-filtered $5^{\circ} \times 5^{\circ}$ data likely suppressed all oceanic eddy activity. To gain some insight into the role of internal oceanic processes in the local LIM, we choose to investigate the spatial structure and spectrum of the noise forcing.

We approximate the noise forcing $\xi$ of SST $\left(T_{A}\right)$ in (2) as $\eta_{S}\left(\eta_{A}\right)$, a residual from the integration of (2) over a short time period ( $\Delta t=1$ day):

$$
\eta(t)=\frac{\mathbf{x}(t+\Delta t)-\mathbf{x}(t)}{\Delta t}-\mathbf{L x}(t) .
$$



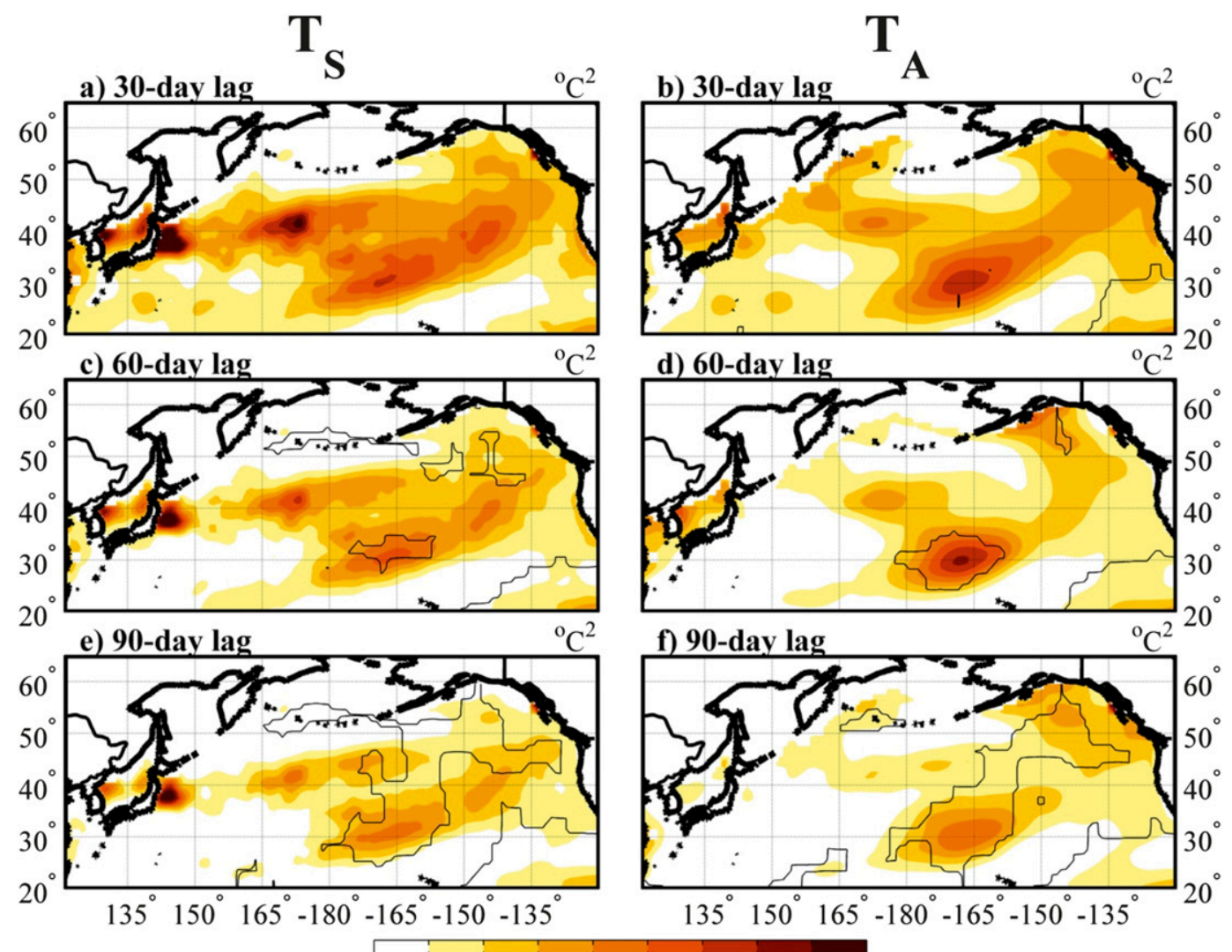

$\begin{array}{llllllll}0.2 & 0.3 & 0.4 & 0.5 & 0.6 & 0.7 & 0.8 & 0.9\end{array}$

FIG. 3. The observed (shading) lag covariance for (left) $T_{S}$ and (right) $T_{A}$ when $\tau$ equals (a),(b) 30 days, (c),(d) 60 days, and (e),(f) 90 days. The contour encloses areas where the difference between the observed lag covariance and that predicted by the local LIM exceeds the $p=0.025$ confidence level from a Monte Carlo test. Note that the local LIM generally underestimates lagged covariance.

Figure 4a shows the power spectra of SST, $\eta_{A}$, and $\eta_{S}$ for 20 randomly sampled points over the North Pacific (shown as dots in Fig. 4c), including five points within the WBC region. Note that $\eta$ is found after rebuilding the local LIM using annual data, which has little to no effect on the main findings (i.e., the full-year $\mathbf{L}$ is similar to the wintertime-only $\mathbf{L}$ but allows for the continuous estimation of $\eta$ ). The power of observed SST variance increases rapidly for $\omega<30 \mathrm{day}^{-1}$, follows the $\omega^{-2}$ curve through $\omega \sim 300 \mathrm{day}^{-1}$ and begins to asymptote as damping dominates for lower frequencies (Frankignoul 1985). Meanwhile, the spectra of $\eta_{S}$, while slightly reddened for $\omega>50 \mathrm{day}^{-1}$, is nearly flat for lower frequencies, implying that the impact of oceanic processes on $T_{S}$ is adequately approximated as white noise for $\omega<$ 50 day $^{-1}$. An $F$ test (not shown) reveals that the power spectra of $\eta_{S}$ does not significantly differ $(p=0.025)$ from a first-order autoregressive (AR1) null hypothesis using a relatively short decorrelation time scale of 15 days. Similar conclusions are reached about $\eta_{A}$, except its decorrelation time scale is an even shorter 5 days, which given the 7-day running mean used for $\mathbf{x}$ can be justified as nearly white noise.

To investigate the extent to which the noise forcing varies across the North Pacific, Figs. $4 \mathrm{~b}$ and $4 \mathrm{c}$ show the diagonal elements of $\mathbf{Q}$, which represent the variances of $T_{A}$ and $T_{S}$ noise forcing, respectively. Figure $4 \mathrm{c}$ shows that $T_{S}$ forcing is maximized in the $\mathrm{WBC}$ region, which represents the aggregate impact on $T_{S}$ forcing from anomalous currents, gradients, and mesoscale eddy activity portrayed by $\xi_{S}$ in (2). To directly compare our model to BB98, the fluctuation-dissipation relation is used to find the amount of $T_{S}$ variance in the absence of $T_{S}$ noise forcing (not shown). Not surprisingly, only $20 \%-30 \%$ of $T_{S}$ variance remains within the WBC, while $60 \%-70 \%$ is retained in the eastern portion of the North Pacific (the latter number is likely an underestimate since the LIM does not have ENSO-forced $T_{A}$ variability; see Fig. 3). Meanwhile, even taking into account the 7-day smoothing, the strongest $T_{A}$ forcing 
a) Power spectra

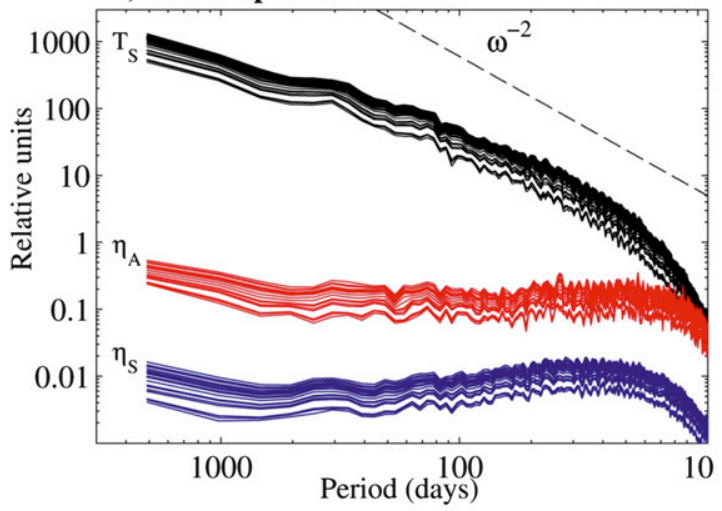

b) $\mathbf{Q}_{\mathbf{A}}$

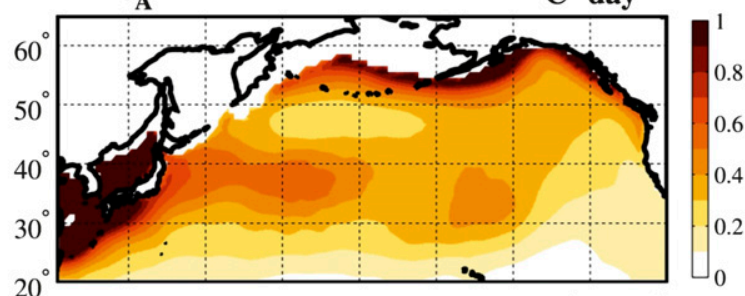

$20^{\circ}$

c) $Q_{S}$

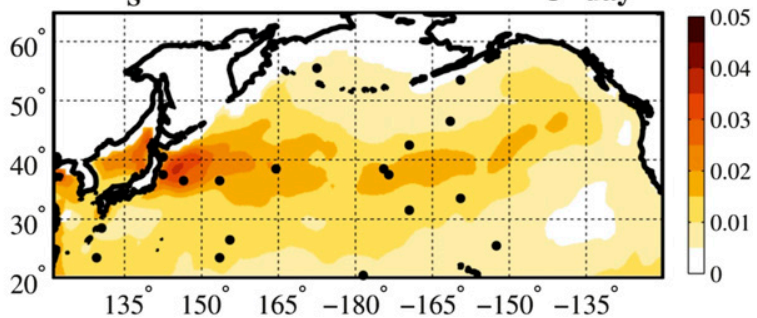

FIG. 4. (a) The normalized power spectra of $T_{S}$ (black), $\eta_{A}$ (red), and $\eta_{S}$ (blue) for 20 randomly sampled points. Note that $\eta$ is determined using a finite differencing approximation shown in (3). The $\omega^{-2}$ line is shown to reference an undamped Markov model. For clarity, $\eta_{A}\left(\eta_{S}\right)$ has been scaled by $0.03(0.003)$. Thus, the values on the $y$ axis are only relative and should be used to note the $\omega$ dependence of each spectrum. The $\mathbf{Q}$ of (b) $T_{A}$ and (c) $T_{S}$ (black dots over the North Pacific show the locations of the 20 randomly sampled points for the normalized power spectra) calculated through (A3) separately at every grid point using $\mathbf{L}$ and the observed covariance structure.

occurs just offshore of the Asian continent and extends over the WBC region (Fig. 4b), associated with the North Pacific storm-track variability (Nakamura et al. 2004). Finally, a secondary maximum of $T_{A}$ noise forcing along the southern coast of Alaska coincides with weak $T_{S}$ variability (cf. Fig. 1a) there, and we do not discuss this further.

\section{b. The role of coupling}

In the previous section, it was shown that the local LIM adequately represents observed extratropical $T_{A}$ and $T_{S}$ coupled variability on weekly time scales over

\section{a) $\sigma_{\mathrm{S}}^{\mathrm{u}} / \sigma_{\mathrm{S}}$, monthly}

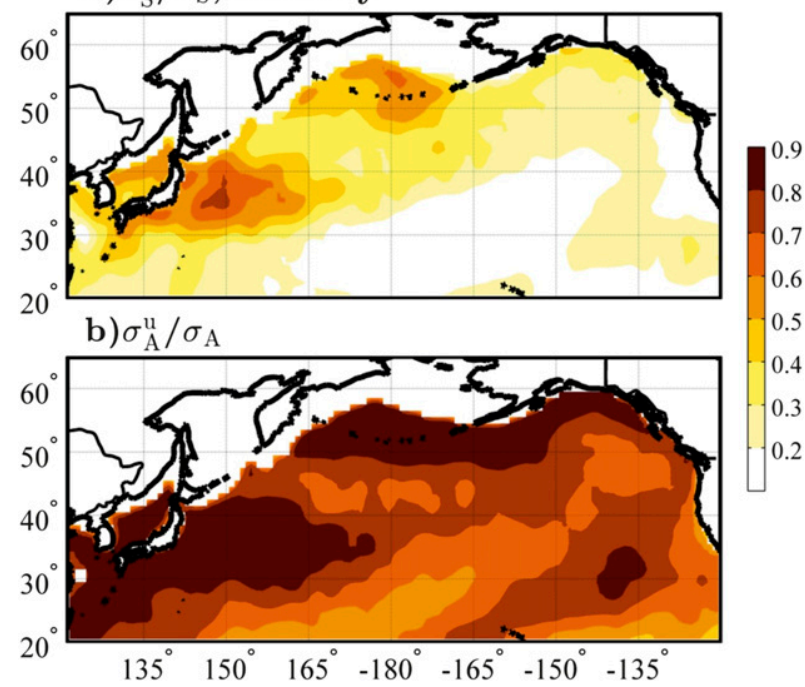

FIG. 5. The fractional amount of retained (a) monthly averaged $T_{S}$ and (b) total $T_{A}$ variability after integrating (2) with the uncoupled operator $\mathbf{L}^{u}$ and noise $\mathbf{Q}^{u}$.

the course of a season. As originally suggested in BB98, coupling boosts persistence of both $T_{A}$ and $T_{S}$ anomalies. However, the nonhomogeneity of the coupling coefficients (cf. Figs. 2b,c) raises the questions: what are the impacts of the differing coupling strength across the North Pacific, and how sensitive are the $T_{A}$ and $T_{S}$ variances to the coupling strength? We approach this question by determining what the variability would be for a system like (2) with the same noise forcing but with uncoupled dynamics $\mathbf{L}^{u}$ and noise $\mathbf{Q}^{u}$ (i.e., where $\mathbf{L}$ is modified to remove the effects of coupling by setting $b=$ $c=0$, and $\mathbf{Q}$ has been modified by setting the off-diagonal elements to 0$)$. We create two synthetic datasets by numerically integrating (2) for 9000 days, with either $\mathbf{L}$ and $\mathbf{Q}$ or $\mathbf{L}^{u}$ and $\mathbf{Q}^{u}$, for each grid point using the numerical method outlined by Penland and Matrosova (1994) and a time step of $2 \mathrm{~h}$. The integration using $\mathbf{L}$ forced by the observed noise covariance yields coupled $T_{S}$ and $T_{A}$ variability that reproduces the observed variance to within $5 \%$ (ensuring the numerical method works properly), while the integration of (2) with $\mathbf{L}^{u}$ yields time series of uncoupled variability, $T_{S}^{u}$ and $T_{A}^{u}$.

Figure 5 shows the ratio of uncoupled to coupled variance for $T_{S}$ and $T_{A}$ (in Fig. 5a; $T_{S}$ and $T_{S}^{u}$ have been monthly averaged before calculating this ratio). Over large areas of the North Pacific, SST variability is nearly eliminated without coupling, with the notable exception of the WBC region where $40 \%-70 \%$ of SST variability is retained. The use of $1^{\circ}$ data implies that the results in the latter region may be underestimated (Taguchi et al. 2009), and in the future it may be worthwhile to redo 
this calculation with higher resolution datasets. A second region with relatively large intrinsic $T_{S}$ variability is located within and just south of the Bering Sea, which is potentially related to oceanic processes associated with variability in the sea ice edge and is not discussed further. In contrast to $T_{S}, T_{A}$ variability is largely retained after uncoupling (Fig. 5b), confirming that the ocean's impact on the atmosphere is much weaker than the atmosphere's impact on SST. A relative minimum in the fraction of uncoupled $T_{A}$ variability occurs from $20^{\circ} \mathrm{N}$, $165^{\circ} \mathrm{E}$ to about $40^{\circ} \mathrm{N}, 150^{\circ} \mathrm{W}$, which is also where $b$ and $c$ are largest (Figs. 2b,c), suggesting this is where local coupling is most important. Meanwhile, nearly all persistent $T_{A}$ variability [represented by $\mathbf{C}(\tau>14$ days $)$ and arising mainly from the feedback by $T_{S}$ ] is eliminated in the absence of coupling (not shown), though note that this is limited to the ENSO teleconnection region east of the date line (see Fig. 3f). Still, Fig. 5 clearly shows that outside of the WBC region, the atmosphere is the ultimate source of air-sea variability.

One caveat in our treatment of air-sea interaction is the absence of wind forcing. Since we do not explicitly consider anomalous wind ( $U$, representing $u$ and $v$ ) in the local LIM, it is possible that $T_{S}$ anomalies generated via Ekman transport are being erroneously incorporated as $T_{S}$ noise forcing (Lee et al. 2008). This would result in an overestimate of intrinsic $T_{S}$ variability shown in Fig. 5a. However, upon reconstructing the local LIM with $u$ i.e., $\left.\mathbf{x}(t)=\left[T_{A}(t) T_{S}(t) u(t)\right]^{\mathrm{T}}\right\}$, which should serve as a good proxy for anomalous Ekman advection in the Kuroshio-Oyashio region, it is found that the amount of $T_{S}$ noise forcing (Fig. 4c) and uncoupled $T_{S}$ variability (Fig. 5a) is essentially unchanged (not shown). In fact, the main change because of the addition of $u$ is in the dynamics of $T_{A}$, while leaving the net atmospheric impact on $T_{S}$ unaltered. In short, the local LIM implicitly includes the impact of $u$ via $T_{A}$ and thus the subsequent impact this may have on $d T_{S} / d t$; any remaining small impact of $u$ (and $v$ ) on $T_{S}$ will be included in the noise.

A secondary caveat in our estimate of intrinsic $T_{S}$ variability arises from the neglect of removing the noiseinduced drift. To the extent that all four coefficients in $\mathbf{L}$ represent wind-dependent fluxes, the coefficients should not be steady since the wind varies much more rapidly than ether $T_{A}$ or $T_{S}$, yielding state-dependent, or multiplicative, noise (Sura et al. 2006; Sura and Newman 2008). State-dependent noise simultaneously weakens coupling and damping; for example, at ocean weather ship (OWS) P, previously located in the Gulf of Alaska, Sura and Newman (2008) estimate that this drift reduces the coupling strength by about $30 \%$ and the SST damping rate by about $10 \%$. Since multiplicative noise is state dependent, it should also be uncoupled. Using the values of the drift and noise obtained by Sura and Newman (2008) for OWS $\mathrm{P}$, uncoupling and eliminating all $T_{A^{-}}$ dependent noise in the SST tendency equation results in a modest $5 \%$ reduction in retained SST variance. Stated differently, our neglect of the noise-induced drift implies a slight overestimate of intrinsic SST variability. Of course, this estimate is for OWS P and may be substantially different in other parts of the basin.

\section{c. Air-sea coupling in fully coupled GCMs}

Recent studies have suggested that air-sea interaction on small scales may oppose the BB98 paradigm in that SST anomalies force changes in the net surface heat flux through modification of the boundary layer wind profile either by changing the low-level stability or as a result of dynamical adjustment (Xie 2004; Samelson et al. 2006; Small et al. 2008). Coupled modeling experiments by Bryan et al. (2010) further suggest that (i) the fidelity to the observed SST-wind stress relationship is greatly improved when an eddy-resolving ocean is used; and (ii) for the version of CCSM3.5 with an eddy-resolving ocean model, increasing the atmospheric resolution provides no additional benefit. Thompson and Kwon (2010) and Kirtman et al. (2012) suggest that the benefit of including ocean eddies also applies to the larger-scale oceanic circulation, not just at the small scale. Collectively, these findings suggest that resolving ocean eddies enhances the realism in depicting air-sea interaction.

To test this hypothesis, we repeat the local-LIM analysis using two recent coupled GCM simulations from CCSM3.5 (Gent et al. 2010) that only differ in their oceanic model resolution. The HR (LR) simulation has an ocean model resolution of $0.1^{\circ}\left(1.0^{\circ}\right)$; both employ the $0.5^{\circ}$ Community Atmosphere Model, version 3, for the atmosphere. Note the HR allows for oceanic eddies, which are parameterized by the large-scale flow in the LR. Figures $6 a$ and $6 \mathrm{~b}$ show the standard deviation of weekly SST anomalies in the LR and HR, respectively. The LR displays a commonly known northward bias in the WBC separation shown by other lower-resolution models (Thompson and Kwon 2010), with the maximum WBC SST variability located around $43^{\circ} \mathrm{N}$ in Fig. 6 a compared to around $38^{\circ} \mathrm{N}$ in Fig. 1a. In contrast, the HR reproduces the latitude of maximum variability better but shows substantially too much SST variability basinwide (Fig. 6b) and appears to be less successful than the LR in representing variability in the ENSO teleconnection/subtropical front region near $35^{\circ} \mathrm{N}$, $150^{\circ} \mathrm{W}$. Both models reproduce the amplitude and structure of $T_{A}$ variance very well (not shown). Figures $2 \mathrm{e}-1$ show the coefficients of $\mathbf{L}$ obtained for both GCM simulations. Both GCMs capture the structure and amplitude of the $T_{A}$ damping $(a)$ and the relative increase 

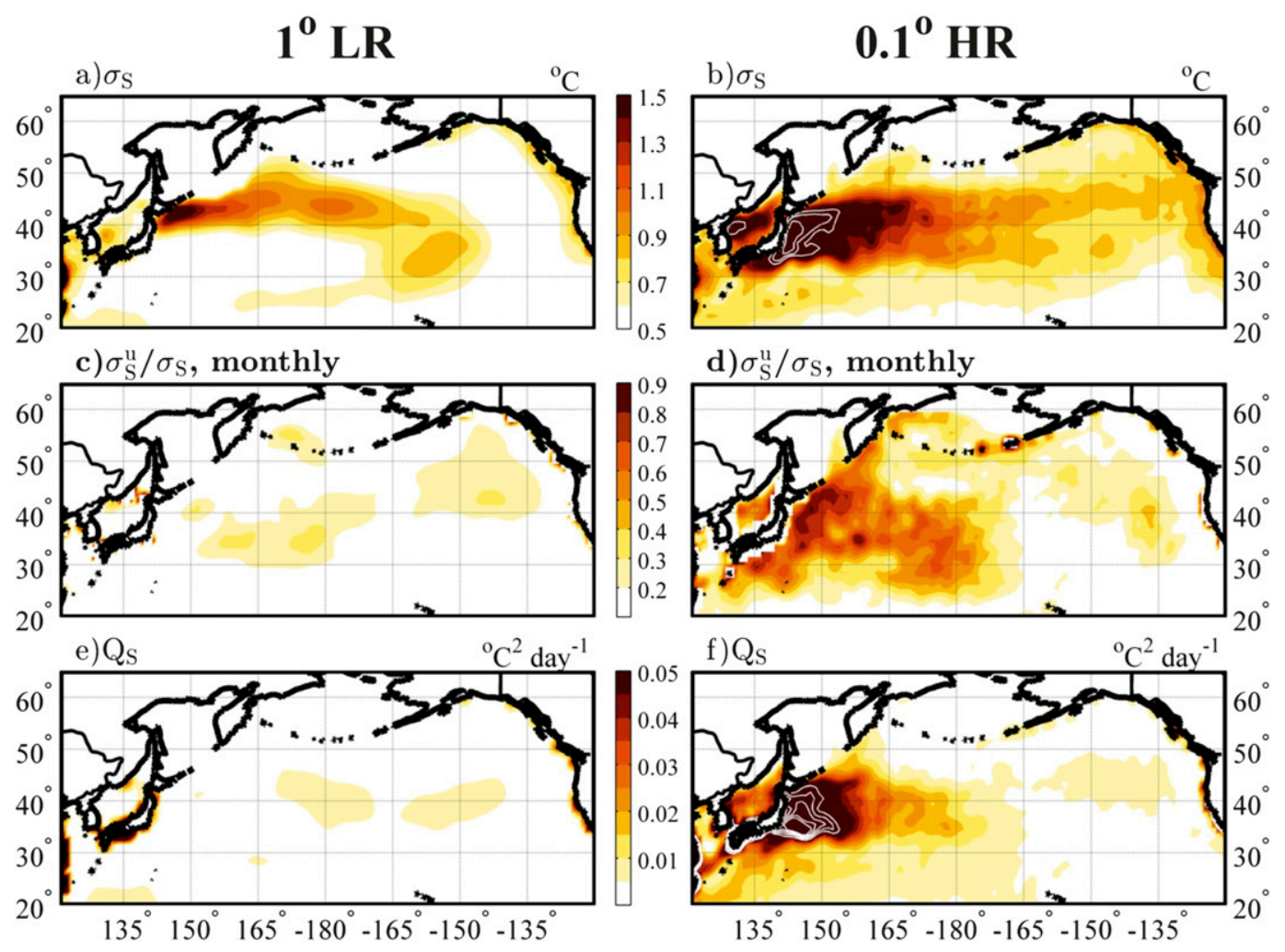

FIG. 6. Standard deviation of weekly averaged, extended winter (NDJFM) $T_{S}$ anomalies from CCSM3.5 with an ocean model resolution of (a) $1^{\circ}$ (LR) and (b) $0.1^{\circ}$ (HR). These can be directly compared to Fig. 1a. The white contours in (b) denote values exceeding the colorbar with a $0.2^{\circ} \mathrm{C}$ increment. (c), (d) As in Fig. 5a, but for (c) LR and (d) HR. (e),(f) As in Fig. 4c, but for (e) LR and (f) HR. The white contours in (f) denote values exceeding the colorbar with a $0.02^{\circ} \mathrm{C}^{2}$ day $^{-1}$ increment.

in $T_{S}$ damping in the subtropics, but both also underestimate the $T_{S}$ damping $(d)$ and the $T_{A}$ effect on $T_{S}(c)$. Meanwhile, uncoupling $L$ from the HR and LR local LIMs yields quite different results: in the LR simulation, there is very little SST variability that is not generated by the atmosphere (Fig. 6c), while $60 \%-80 \%$ of SST variability in the HR is independent of the atmosphere over large portions of the western North Pacific (Fig. 6d). This stark difference appears to be due to different $T_{S}$ noise forcing for each model (Figs. 6e,f), since compared to observations (cf. Fig. 4c), HR overestimates $T_{S}$ noise forcing within the WBC by a factor of 5, while LR grossly underestimates it. No such difference exists for the models' $T_{A}$ noise forcing, which is comparable to observations (not shown).

\section{The importance of nonlocal factors}

The benefit of using a local model is its simplicity, but one potential concern is that the local LIM might convolve nonlocal processes in the coefficients contained within $\mathbf{L}$, as would occur if coefficient $a(d)$ had a dependence on $\nabla T_{A}\left(\nabla T_{S}\right)$. For example, consider the nonlocal interaction as depicted schematically in Fig. 7 for two hypothetical regions A and B. The coefficients of the local LIM (Fig. 2) are meant to represent processes 1-4 ( $a \rightarrow 1, d \rightarrow 2, c \rightarrow 3$, and $b \rightarrow 4$ ) in Fig. 7, which portray radiative and thermal heat flux anomalies as posited by BB98. But the $a-d$ coefficients may also implicitly represent nonlocal processes $5-12$, especially in regions where advection is important (e.g., WBC). Additionally, processes 7-10 in Fig. 7 represent the indirect remote interaction of $T_{A}$ and $T_{S}$ through changes in $\nabla T_{A}, \nabla T_{S}$, cloud cover, and wind or moisture anomalies that are not represented by the local LIM but may improve the nonlocal model's predicted covariance.

We explore explicitly resolving nonlocal interactions in this section by constructing a LIM from a multidimensional state vector consisting of anomalies averaged within certain regions, or boxes, following Shin et al. (2010). The boxes are chosen based on (i) SST variance (Fig. 1a) and (ii) the patterns of the leading two empirical orthogonal functions (EOFs) of weekly wintertime North Pacific $\left(20^{\circ}-65^{\circ} \mathrm{N}\right)$ SST anomalies. The two EOFs, 


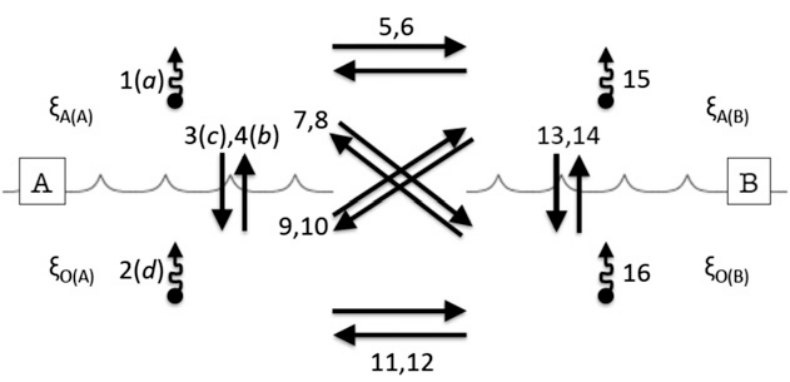

FIG. 7. Schematic of interactions in hypothetical $T_{A}$ and $T_{S}$ coupled model of two boxes, A and B. Processes are arbitrarily labeled for use within the discussion.

which are the only statistically separable ones and explain a combined $43 \%$ of the variance, are shown in Fig. 8 along with the boxes. The $T_{S}$ and $T_{A}$ anomalies are averaged within each box to create the state vector $\mathbf{X}^{B}$. Each box contains the same amount of grid points, but note that variability in the west may have smaller-scale, higherfrequency features (see Hosoda and Kawamura 2005). We estimate the dynamical operator B (to distinguish from $\mathbf{L}$ in the local LIM) through (A1) using the same procedure as for $\mathbf{L}$ (7-day running mean; $\tau=7$ days). Then $\mathbf{B}$ is used to generate the predicted lag covariance out to 90 days through (A2). Hereafter, we refer to the nonlocal LIM as the box LIM. For direct comparison, we also fit a local LIM separately to each box denoting the resulting operators $\mathbf{L}^{B}$. We can then explore whether the local LIM adequately represents the additional complexity of the box LIM and in particular the extent to which the dynamics and coupling are truly local.

We first address how the number of boxes contained in $\mathbf{X}^{B}$ affects forecast skill. We design five experiments, shown in Table 1 , by varying the combination of boxes that comprise $\mathbf{X}^{B}$ from a total of 2 to 5. Experiment (expt) 1 starts by using just two boxes, 1 and 4 , which are used in all the other experiments. Figure 9 illustrates the impact of adding additional boxes with the 1-90-day forecast skill of $T_{S}$ at boxes 1 (Gulf of Alaska) and 4 (WBC region) for all experiments. Additionally, Table 1 shows the day-90 skill for $T_{S}$ and $T_{A}$. The skill is cross validated using independent data as outlined in Winkler et al. (2001). Figure 9 shows a general increase in skill, mainly in box 1 , as additional boxes are added. However, the increase is not steady as it is most rapid from expt 1 through expt 3 but negligible once $\mathbf{X}^{B}$ contains more than four boxes. Several four-box variations of $\mathbf{X}^{B}$, with and without boxes 1 and 4 , support this (not shown). Of all boxes, box 4 skill shows the least improvement with the addition of more boxes, implying that its dynamics are less affected by remote interaction

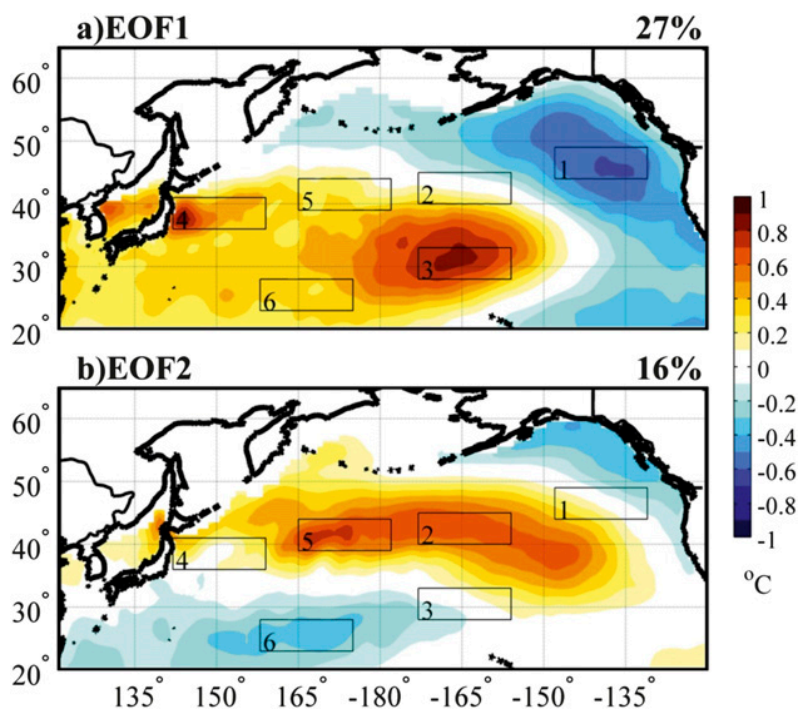

FIG. 8. The leading two EOFs of weekly averaged, wintertime (NDJFM) SST anomalies over the North Pacific $\left(20^{\circ}-60^{\circ} \mathrm{N}, 120^{\circ} \mathrm{E}-\right.$ $\left.120^{\circ} \mathrm{W}\right)$. Boxes indicate the averaging regions used to build the box LIM (see text). Values in the top right show the percent of variance explained by the EOF. Note that only these two EOFs are statistically separable using the technique of North et al. (1982).

though it is still important in elevating the skill of other boxes (such as box 1).

We evaluate the box LIM further by comparing it to the local LIM. Figure 10 shows the 1-90-day skill across all boxes for $T_{S}$ and $T_{A}$ using $\mathbf{B}$ from expt 3 and $\mathbf{L}^{B}$ for each box, as a pattern anomaly correlation with observations. We use expt 3 since it captures almost all the skill achievable from the box LIM. Adding nonlocal interaction boosts skill in both $T_{S}$ and $T_{A}$ forecasts. Although this is true for all boxes (not shown), the effect is relatively larger in boxes 1 and 3 (not shown). Next, we recalculate skill after isolating the local processes of $\mathbf{B}$ (setting all nonlocal processes to zero) and denoting this operator $\mathbf{B}^{1 \mathrm{~d}}$, shown in Fig. 10. The skill using $\mathbf{B}^{1 \mathrm{~d}}$ is worse than $\mathbf{L}^{B}$ for both $T_{A}$ and $T_{S}$, implying that the local-LIM coefficients $a-d$ implicitly incorporate some

TABLE 1 . Box-LIM expt $1-5$ constructed by building the state vector $\mathbf{X}^{B}$ from the specified boxes (see Fig. 8). Also shown is the 90-day cross-validated forecast skill, as an anomaly correlation, at boxes 1 and 4 . The cross-validated 90-day local-LIM skill is shown in parentheses.

\begin{tabular}{ccccccc}
\hline \hline & \multirow{2}{*}{$\begin{array}{c}\text { Boxes } \\
\text { Expt }\end{array}$} & \multicolumn{2}{c}{ Day-90 skill (box 1) } & & \multicolumn{2}{c}{ Day-90 skill (box 4) } \\
\cline { 6 - 7 } \cline { 6 - 7 } & & $T_{S}$ & $T_{A}$ & & $T_{S}$ & $T_{A}$ \\
\hline 1 & 1,4 & $0.60(0.63)$ & $0.42(0.30)$ & & $0.47(0.45)$ & $0.23(0.12)$ \\
2 & $1,2,4$ & 0.68 & 0.49 & & 0.47 & 0.23 \\
3 & $1-4$ & 0.71 & 0.52 & & 0.49 & 0.24 \\
4 & $1-5$ & 0.71 & 0.52 & & 0.48 & 0.24 \\
5 & $1-4,6$ & 0.73 & 0.54 & & 0.49 & 0.23 \\
\hline
\end{tabular}




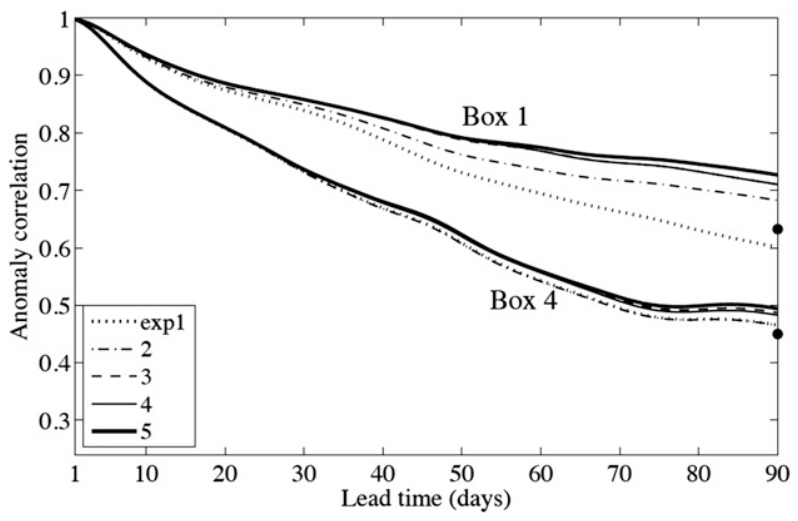

FIG. 9. (a) Cross-validated skill as a function of lead time for box 1 and box $4 T_{S}$ (anomaly correlation with observations) using B from the five experiments shown in Table 1 . The black dots indicate the day- 90 skill of boxes 1 and 4 in the local LIM. In box 1 the dashed line showing the skill of expt 3 is masked by the solid line showing expt 4 .

nonlocal processes. Separately suppressing remote $T_{A}$ (processes 5 and 6 in Fig. 7) and $T_{S}$ (processes 11 and 12) interactions indicates the absence of remote $T_{A}$ interaction is responsible for most of the skill degradation (not shown), which is physically plausible on the relatively short time scales we consider.

Finally, we investigate whether the local LIM and box LIM differ in their treatment of coupling. The observed and predicted lagged cross covariance using $\mathbf{B}$ and $\mathbf{L}^{B}$ is shown in Fig. 11 for boxes 3 (east-central North Pacific) and 4 (WBC region). In both boxes, the cross covariance is maximized when $T_{A}$ leads $T_{S}$ by 5-7 days, as expected when $T_{A}$ forces $T_{S}$. However, even though weekly $T_{S}$ and $T_{A}$ variability is comparable between boxes 3 and 4 (cf. Figs. 1a,b), the cross covariance is much higher at box 3 across all lags, implying a much stronger local coupling here. In box 4 (Fig. 11b), the local LIM and box LIM both predict the cross covariance within the $95 \%$ confidence range based on 200 iterations of a Monte Carlo simulation, though both underestimate the cross covariance when $T_{S}$ leads by more than 60 days. Meanwhile, the box LIM outperforms the local LIM at box 3 (Fig. 11a), though both underestimate the magnitude of the cross covariance. Note that box 3 has a welldocumented ENSO teleconnection that may explain the difference between the box-LIM and local-LIM prediction there. Lastly, we solve the fluctuation-dissipation relation in (A3) by removing all processes that represent coupling in $\mathbf{B}$ and $\mathbf{L}^{B}$, denoting the uncoupled operators $\mathbf{B}^{u}$ and $\mathbf{L}^{B, u}$, respectively. Figure 12 shows that the fraction of retained $T_{S}$ variance is nearly identical between the box LIM and local LIM and also confirms that the WBC region (box 4) has substantially more uncoupled SST variance relative to the other boxes. There

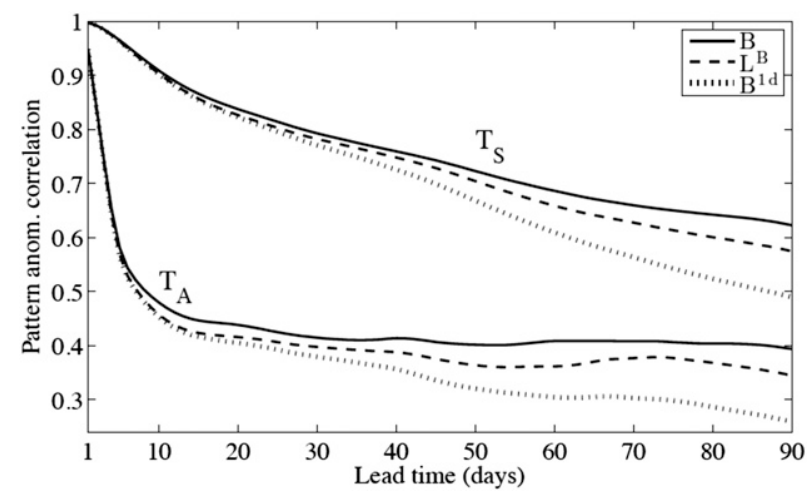

FIG. 10. Cross-validated pattern anomaly correlation with observations of $T_{S}$ and $T_{A}$ using $\mathbf{B}$ (solid), $\mathbf{L}^{B}$ (dash), and $\mathbf{B}^{1 \mathrm{~d}}$ (dotted) from expt 3 .

are some minor discrepancies between uncoupled $T_{A}$ variance among boxes, but this disappears upon averaging over all boxes and could be due to uncertainties in the coefficients of $\mathbf{B}$ and $\mathbf{L}^{B}$.

\section{Conclusions}

A coupled local LIM of $T_{A}$ and $T_{S}$ fit to observations predicts lagged covariance statistics well on time scales up to a season. The main additions to the findings of BB98 are (i) the model does surprisingly well in dynamically active oceanic regions but only with the inclusion of a substantial amount of $T_{S}$ noise forcing, and (ii) local coupling varies very strongly over the basin, generally being more important as one moves east across the North Pacific. Uncoupling the model's simple dynamics results in a near complete elimination of SST variability everywhere away from the WBC region, while $T_{A}$ variability is only slightly affected. In the WBC region, approximately $50 \%$ of monthly $T_{S}$ variability appears intrinsic to the ocean. It is important to recall that our use of the term coupling does not differentiate between the relative magnitude of $T_{S}$ versus $T_{A}$ forcing, as even in a strongly coupled region like the eastern North Pacific, nearly all SST variability is driven by $T_{A}$. Thus, in this context and in BB98, strong coupling mainly drives an increase in the persistence of $T_{A}$ and $T_{S}$ anomalies.

We apply the same analysis to two coupled GCMs using the same atmospheric GCM but either a highresolution $\left(0.1^{\circ}\right)$ or low-resolution $\left(1.0^{\circ}\right)$ ocean model. We find that the $0.1^{\circ}$ model generates more SST variability compared to the $1.0^{\circ}$ model and observations but better reproduces the latitude of maximum variability within the WBC (cf. Fig. 1a with Figs. 6a,b). By uncoupling $\mathbf{L}$ in the local LIM of each GCM, we find the 

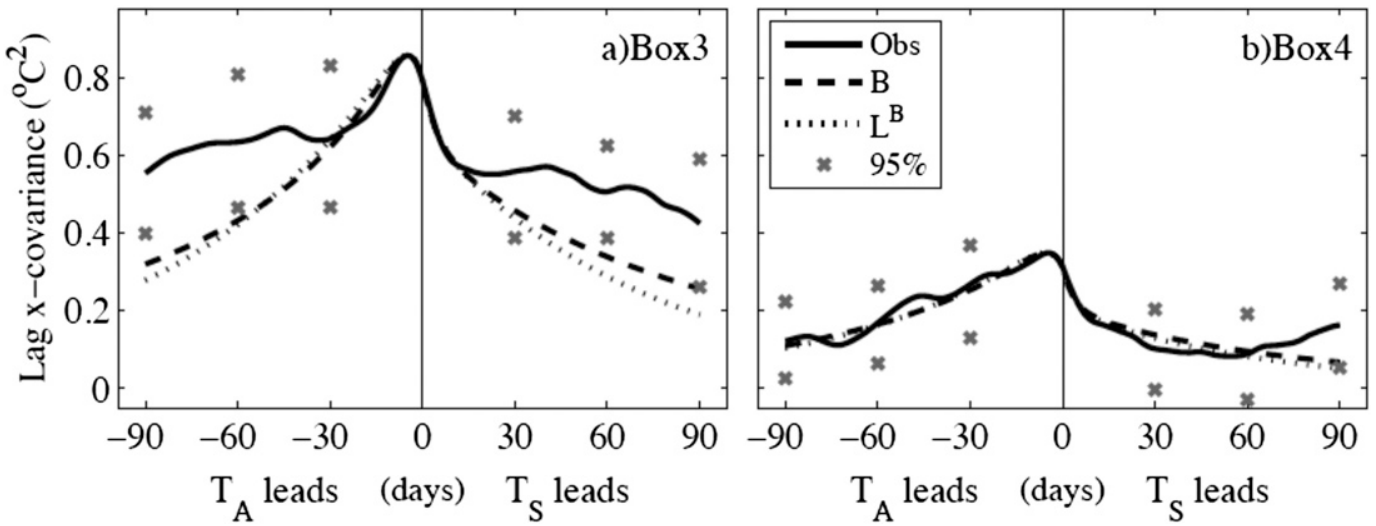

FIG. 11. Observed (solid) and predicted (using B from expt 3, dashed; using $\mathbf{L}^{B}$, dotted) lag cross covariance between $T_{S}$ and $T_{A}$ as a function of lag time for (a) box 3 (east-central Pacific) and (b) box 4 (WBC region). The $T_{A}$ leads (lags) $T_{S}$ when the lag time is negative (positive). Gray crosses indicate the upper $(97.5 \%)$ and lower $(2.5 \%)$ ranges using 200 iterations of a Monte Carlo test.

$0.1^{\circ}$ ocean model shows substantially more intrinsic SST variability within the $\mathrm{WBC}$ compared to the $1^{\circ}$ model. This difference is partially explained by the near absence of $T_{S}$ noise forcing within the $1^{\circ}$, while the $0.1^{\circ}$ model generally overestimates this quantity within the WBC (cf. Figs. 4a and 6e,f). Though the large overestimate of $T_{S}$ variance within the $0.1^{\circ}$ model is certainly a caveat that makes it difficult to choose one GCM as superior over the other, it is clear that resolving ocean eddies properly in future coupled GCMs will likely yield a significant impact on their depiction of air-sea interaction.

We remove the one-dimensional constraint of the local LIM by creating a box LIM based on area-averaged $T_{A}$ and $T_{S}$ anomalies located in regions of high SST variance (Fig. 8). The skill of the box LIM shows improvement over its local LIM equivalent in both $T_{S}$ and $T_{A}$. However, subsequent modification of the box LIM to remove nonlocal interaction shows a substantial drop in skill, suggesting that the local-LIM coefficients implicitly incorporate some nonlocal processes (Fig. 10). Furthermore, the role of nonlocal interaction affects the eastern boxes more than those in the west, likely resulting from a significant portion of ENSO forcing that is not explicitly represented by our box-LIM framework. A logical next step is to explicitly include the tropical Pacific in the state vector $\mathbf{X}^{B}$ as in Newman et al. (2003). Meanwhile, concerning coupling, the box LIM and local LIM yield nearly identical results (Fig. 12).

Finally, the concept of "retained" SST variance deserves some discussion. In the purely passive model of BB98, there is no retained SST variability if the dynamics are uncoupled. For this reason, extreme caution was suggested in the design of SST-forced AGCM experiments. The results herein suggest that enough independent SST variability exists within the WBC region so that it is not unreasonable to prescribe SST anomalies there. This supports the approach of experiments by Yulaeva et al. (2001), Liu and Wu (2004), Minobe et al. (2008), and Kwon et al. (2011), all of which target the WBC by forcing with either SST, oceanic heat flux convergence, or oceanic mixed-layer heat content anomalies. Note, however, that even in this region, approximately $50 \%$ of SST variability is coupled to the atmosphere, so the problem of forcing an atmospheric GCM with $T_{A}$-driven SST anomalies cannot be ignored. Even though we have shown that regions within the WBC experience ocean-driven SST variability, the methods in this study are insufficient in determining how these retained anomalies influence the atmosphere. Clearly, Fig. 5b suggests the atmospheric response must be significantly nonlocal, as alluded to by Frankignoul et al. (2011) and Taguchi et al. (2012). Higher-order

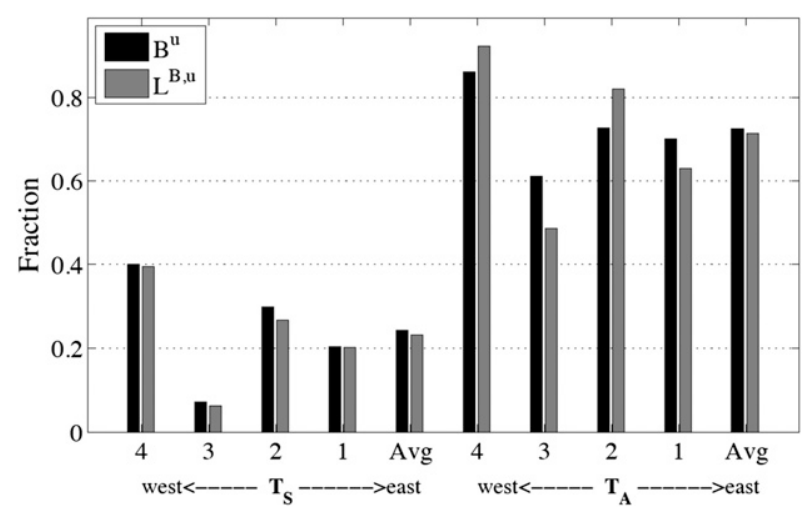

FIG. 12. The fraction of $T_{S}$ and $T_{A}$ variance retained after uncoupling $\mathbf{B}$ (from expt 3 , black) and $\mathbf{L}^{B}$ (gray) at every box. Also shown is the average across all boxes for $T_{S}$ and $T_{A}$. 
models are currently being developed to determine whether the intrinsic SST anomalies exert a simple boundary layer atmospheric response that is quickly overridden with intrinsic atmospheric variability or a deeper response that could potentially influence largescale atmospheric modes, possibly leading to longerterm predictability.

Acknowledgments. The authors thank J. Barsugli, C. Frankignoul, D. Vimont, F. Bryan, and three anonymous reviewers for insightful comments. C. Hannay (NCAR) helped in acquiring the CCSM4 output. Funding for DS and MN was provided by NSF Grant 1035423.

\section{APPENDIX}

\section{Estimating the LIM Coefficients}

Using LIM, we assume a stochastically forced system with stationary statistics and dynamics that are linear, or can be approximated as linear functions of $T_{A}$ and $T_{S}$ (Sura and Newman 2008). Intuitively, $T_{A}$ and $T_{S}$ are chosen because $T_{S}$ variability largely depends on the net turbulent heat flux $F_{\text {net }}$ in which $T_{A}$ is a dominant factor (Cayan 1992; Alexander and Scott 1997). Other variables that are important to $F_{\text {net }}$, such as specific humidity, can to some degree be parameterized as a function of $T_{A}$. After solving the discretized form of (2) for $\mathbf{x}(t)$, multiplying the result by $\mathbf{x}(t+\tau)$ (where $\tau$ is a lag time of 7 days) and taking the expectation (denoted by $\langle\cdot\rangle$ ), $\mathbf{L}$ is estimated as

$$
\mathbf{L}=\frac{1}{\tau} \ln \left[\mathbf{C}(\tau) \mathbf{C}(0)^{-1}\right]
$$

where $\mathbf{C}(\tau)=\left\langle\mathbf{x}(t+\tau) \mathbf{x}(t)^{\mathrm{T}}\right\rangle$ is the $\tau$-lag covariance and $\mathbf{C}(0)=\left\langle\mathbf{x}(t) \mathbf{x}(t)^{\mathrm{T}}\right\rangle$ is the zero-lag covariance. The choice of $\tau$ is relatively subjective, but it is a key test of the LIM to consider a range of $\tau$ and verify that $\mathbf{L}$ does not significantly change (Penland and Sardeshmukh 1995). However, when altering $\tau$, it is sometimes necessary to filter the data to remove very high-frequency variability. We use a range of $\tau=[1,3,5,7,11,15$, and 21] and accordingly a boxcar filter of the same length as $\tau$ to smooth $\mathbf{x}$. For $\tau<7$ days, $\mathbf{L}$ is not constant; on the other hand, $\mathbf{L}$ is nearly unchanged for $\tau>7$, so we set $\tau=7$.

Since the noise forcing in (2) is unpredictable, the most likely evolution of $\mathbf{x}(t)$ at time $t+\tau$ is (Penland and Sardeshmukh 1995)

$$
\mathbf{x}(t+\tau)=\exp (\mathbf{L} \tau) \mathbf{x}(t) .
$$

Eigenanalysis of $\mathbf{L}$ yields eigenvectors and potentially complex eigenvalues, which together characterize the eigenmodes of (A2) (Penland 1996; Penland and Sardeshmukh 1995). For the local LIM, we have two eigenmodes and find that the accompanying eigenvalues are real and negative, implying anomaly decay to climatology over a finite time. This is not true for the box LIM, which has several complex eigenmodes, though all have negative real parts.

The LIM explains the balance of external forcing $\xi$ that is constantly being damped back toward climatology by $\mathbf{L}$, which is quantified by the fluctuation-dissipation relation (FDR; Penland and Matrosova 1994):

$$
\frac{d \mathbf{C}(0)}{d t}=\mathbf{L C}(0)+\mathbf{C}(0) \mathbf{L}^{\mathrm{T}}+\mathbf{Q}=0
$$

where $\mathbf{Q}=\left\langle\xi \xi^{\mathrm{T}}\right\rangle d t$ (Penland 1996), or

$$
\mathbf{Q}=\left[\begin{array}{ll}
\left\langle\xi_{A} \xi_{A}\right\rangle & \left\langle\xi_{A} \xi_{S}\right\rangle \\
\left\langle\xi_{S} \xi_{A}\right\rangle & \left\langle\xi_{S} \xi_{S}\right\rangle
\end{array}\right] d t
$$

where $\xi_{A}\left(\xi_{S}\right)$ represents the $T_{A}\left(T_{S}\right)$ noise forcing, and the diagonal elements of $\mathbf{Q}$ are referred to as the $T_{A}\left(T_{S}\right)$ noise covariance $\mathbf{Q}_{A}\left(\mathbf{Q}_{S}\right)$.

In practice, $\mathbf{L}$ is determined through (A1), and $\mathbf{Q}$ is determined as a residual in (A3) under the assumption that the system's statistics are stationary, $d \mathbf{C}(0) / d t=0$ (Penland 1996). Additionally, $\mathbf{L}$ and $\mathbf{Q}$ can depend on the annual cycle, which can influence the quality of the forecast in (A2) (Penland and Ghil 1993). We recalculate $\mathbf{L}$ and $\mathbf{Q}$ using all months and just warm months (April-October) and note at least two substantial differences between the extended winter-only LIM. First, the summer LIM has a generally weaker $\mathbf{Q}$ consistent with reduced atmospheric variability during the warm months. Second, the model skill is lower, likely as a result of the elevated role of nonlinear effects such as cloud cover (e.g., Park et al. 2006) in dictating SST variability during the summer. Finally, it is notable that the local noise approximation of BB98 and FH77 holds relatively well, as the off-diagonal elements of $\mathbf{Q}$ contribute little to the FDR balance (not shown).

\section{REFERENCES}

Alexander, M., 1992: Midlatitude atmosphere-ocean interaction during El Niño. Part I: The North Pacific Ocean. J. Climate, 5, 944-958.

_ 2010: Extratropical air-sea interaction, SST variability and the Pacific decadal oscillation. Climate Dynamics: Why Does Climate Vary?, Geophys. Monogr., Vol. 189, Amer. Geophys. Union, 123-148.

— - and C. Deser, 1995: A mechanism for the recurrence of wintertime midlatitude SST anomalies. J. Phys. Oceanogr., 25, 122-137.

_ , and J. Scott, 1997: Surface flux variability over the North Pacific and North Atlantic Oceans. J. Climate, 10, 2963-2978. 
,-- -, and C. Deser, 2000: Processes that influence sea surface temperature and ocean mixed layer depth variability in a coupled model. J. Geophys. Res., 105 (C7), 16823-16842.

— I. Bladé, M. Newman, J. Lanzante, N. Lau, and J. Scott, 2002: The atmospheric bridge: The influence of ENSO teleconnections on air-sea interaction over the global oceans. J. Climate, 15, 2205-2232.

Barsugli, J., and D. Battisti, 1998: The basic effects of atmosphereocean thermal coupling on midlatitude variability. J. Atmos. Sci., 55, 477-493.

Bjerknes, J., 1964: Atlantic air-sea interaction. Advances in Geophysics, Vol. 10, Academic Press, 1-82.

Brayshaw, D., B. Hoskins, and M. Blackburn, 2009: The basic ingredients of the North Atlantic storm track. Part I: Land-sea contrast and orography. J. Atmos. Sci., 66, 2539-2558.

—,- , and — 2011: The basic ingredients of the North Atlantic storm track. Part II: Sea surface temperatures. J. Atmos. Sci., 68, 1784-1805.

Bretherton, C., and D. Battisti, 2000: Interpretation of the results from atmospheric general circulation models forced by the time history of the observed sea surface temperature distribution. Geophys. Res. Lett., 27, 767-770.

Bryan, F., R. Tomas, J. Dennis, D. Chelton, N. Loeb, and J. McClean, 2010: Frontal scale air-sea interaction in highresolution coupled climate models. J. Climate, 23, 6277-6291.

Cayan, D., 1992: Latent and sensible heat flux anomalies over the northern oceans: Driving the sea surface temperature. J. Phys. Oceanogr., 22, 859-881.

Chelton, D., M. Schlax, M. Freilich, and R. Milliff, 2004: Satellite measurements reveal persistent small-scale features in ocean winds. Science, 303, 978-983.

Deser, C., M. Alexander, and M. Blackmon, 1999: Evidence for a wind-driven intensification of the Kuroshio Current Extension from the 1970s to the 1980s. J. Climate, 12, 1697-1706.

Diaz, H., M. Hoerling, and J. Eischeid, 2001: ENSO variability, teleconnections and climate change. Int. J. Climatol., 21, 18451862.

Dong, S., and K. A. Kelly, 2004: Heat budget in the Gulf Stream region: The importance of heat storage and advection. J. Phys. Oceanogr., 34, 1214-1231.

Ferranti, L., F. Molteni, and T. Palmer, 1994: Impact of localized tropical and extratropical SST anomalies in ensembles of seasonal GCM integrations. Quart. J. Roy. Meteor. Soc., 120, 1613-1645.

Frankignoul, C., 1985: Sea surface temperature anomalies, planetary waves, and air-sea feedback in the middle latitudes. Rev. Geophys., 23, 357-390.

__ , and K. Hasselmann, 1977: Stochastic climate models, Part II: Application to sea-surface temperature anomalies and thermocline variability. Tellus, 29, 289-305.

_ latitude sea surface temperature anomalies. J. Phys. Oceanogr., 13, 1131-1145.

_ , and E. Kestenare, 2002: The surface heat flux feedback. Part I: Estimates from observations in the Atlantic and the North Pacific. Climate Dyn., 19, 633-647.

—, N. Sennéchael, Y. Kwon, and M. Alexander, 2011: Influence of the meridional shifts of the Kuroshio and the Oyashio Extensions on the atmospheric circulation. J. Climate, 24, 762777.

Gent, P., S. Yeager, R. Neale, S. Levis, and D. Bailey, 2010: Improvements in a half degree atmosphere/land version of the CCSM. Climate Dyn., 34, 819-833.
— , and Coauthors, 2011: The Community Climate System Model version 4. J. Climate, 24, 4973-4991.

Hall, A., and S. Manabe, 1997: Can local linear stochastic theory explain sea surface temperature and salinity variability? Climate Dyn., 13, 167-180.

Hoerling, M., and A. Kumar, 2002: Atmospheric response patterns associated with tropical forcing. J. Climate, 15, 2184-2203.

Hosoda, K., and H. Kawamura, 2005: Seasonal variation of space/ time statistics of short-term sea surface temperature variability in the Kuroshio region. J. Oceanogr., 61, 709-720.

Kelly, K., 2004: The relationship between oceanic heat transport and surface fluxes in the western North Pacific: 1970-2000. J. Climate, 17, 573-588.

Kirtman, B., and Coauthors, 2012: Impact of ocean model resolution on CCSM climate simulations. Climate Dyn., 39, 1303-1328.

Kossin, J., and D. Vimont, 2007: A more general framework for understanding Atlantic hurricane variability and trends. Bull. Amer. Meteor. Soc., 88, 1767-1782.

Kushnir, Y., and I. Held, 1996: Equilibrium atmospheric response to North Atlantic SST anomalies. J. Climate, 9, 1208-1220.

- W. Robinson, I. Bladé, N. Hall, S. Peng, and R. Sutton, 2002: Atmospheric GCM response to extratropical SST anomalies: Synthesis and evaluation. J. Climate, 15, 2233-2256.

Kwon, Y., M. Alexander, N. Bond, C. Frankignoul, H. Nakamura, B. Qiu, and L. Thompson, 2010: Role of the Gulf Stream and Kuroshio-Oyashio systems in large-scale atmosphere-ocean interaction: A review. J. Climate, 23, 3249-3281.

, C. Deser, and C. Cassou, 2011: Coupled atmosphere-mixed layer ocean response to ocean heat flux convergence along the Kuroshio Current Extension. Climate Dyn., 36, 2295-2312.

Lee, D., Z. Liu, and Y. Liu, 2008: Beyond thermal interaction between ocean and atmosphere: On the extratropical climate variability due to the wind-induced SST. J. Climate, 21, 20012018.

Liu, Z., and L. Wu, 2004: Atmospheric response to North Pacific SST: The role of ocean-atmosphere coupling. J. Climate, 17, 1859-1882.

Miller, A. J., D. R. Cayan, T. P. Barnett, N. E. Graham, and J. M. Oberhuber, 1994: Interdecadal variability of the Pacific Ocean: Model response to observed heat flux and wind stress anomalies. Climate Dyn., 9, 287-302.

Minobe, S., A. Kuwano-Yoshida, N. Komori, S. Xie, and R. Small, 2008: Influence of the Gulf Stream on the troposphere. Nature, 452, 206-209.

Mitsudera, H., B. Taguchi, Y. Yoshikawa, H. Nakamura, T. Waseda, and T. Qu, 2004: Numerical study on the Oyashio water pathways in the Kuroshio-Oyashio confluence. J. Phys. Oceanogr., 34, 1174-1196.

Mosedale, T., D. Stephenson, and M. Collins, 2005: Atlantic atmosphere-ocean interaction: A stochastic climate modelbased diagnosis. J. Climate, 18, 1086-1095.

Nakamura, H., G. Lin, and T. Yamagata, 1997: Decadal climate variability in the North Pacific during the recent decades. Bull. Amer. Meteor. Soc., 78, 2215-2225.

, T. Sampe, Y. Tanimoto, and A. Shimpo, 2004: Observed associations among storm tracks, jet streams and midlatitude oceanic fronts. Earth's Climate: The Ocean-Atmosphere Interaction, Geophys. Monogr., Vol. 147, Amer. Geophys. Union, 329-345.

- - A. Goto, W. Ohfuchi, and S. Xie, 2008: On the importance of midlatitude oceanic frontal zones for the mean state and dominant variability in the tropospheric circulation. Geophys. Res. Lett., 35, L15709, doi:10.1029/2008GL034010. 
Namias, J., 1959: Recent seasonal interactions between North Pacific waters and the overlying atmospheric circulation. J. Geophys. Res., 64 (6), 631-646.

Newman, M., P. Sardeshmukh, C. R. Winkler, and J. S. Whitaker, 2003: A study of subseasonal predictability. Mon. Wea. Rev., 131, 1715-1732.

Nonaka, M., H. Nakamura, B. Taguchi, N. Komori, A. KuwanoYoshida, and K. Takaya, 2009: Air-sea heat exchanges characteristic of a prominent midlatitude oceanic front in the south Indian Ocean as simulated in a high-resolution coupled GCM. J. Climate, 22, 6515-6535.

North, G., T. Bell, R. Cahalan, and F. Moeng, 1982: Sampling errors in the estimation of empirical orthogonal functions. Mon. Wea. Rev., 110, 699-706.

Park, S., C. Deser, and M. Alexander, 2005: Estimation of the surface heat flux response to sea surface temperature anomalies over the global oceans. J. Climate, 18, 4582-4599.

— M. Alexander, and C. Deser, 2006: The impact of cloud radiative feedback, remote ENSO forcing, and entrainment on the persistence of North Pacific sea surface temperature anomalies. J. Climate, 19, 6243-6261.

Pegion, K., and P. Sardeshmukh, 2011: Prospects for improving subseasonal predictions. Mon. Wea. Rev., 139, 36483666.

Peng, S., L. Mysak, H. Ritchie, J. Derome, and B. Dugas, 1995: The differences between early and midwinter atmospheric responses to sea surface temperature anomalies in the northwest Atlantic. J. Climate, 8, 137-157.

— W. Robinson, and M. Hoerling, 1997: The modeled atmospheric response to midlatitude SST anomalies and its dependence on background circulation states. J. Climate, 10, 971-987.

Penland, C., 1989: Random forcing and forecasting using principal oscillation pattern analysis. Mon. Wea. Rev., 117, 2165-2185.

—- 1996: A stochastic model of IndoPacific sea surface temperature anomalies. Physica D, 98, 534-558.

_ , and M. Ghil, 1993: Forecasting Northern Hemisphere 700-mb geopotential height anomalies using empirical normal modes. Mon. Wea. Rev., 121, 2355-2372.

_ _ and L. Matrosova, 1994: A balance condition for stochastic numerical models with application to the El Niño-Southern Oscillation. J. Climate, 7, 1352-1372.

_- and P. Sardeshmukh, 1995: The optimal growth of tropical sea surface temperature anomalies. J. Climate, 8, 1999-2024.

Qiu, B., 2000: Interannual variability of the Kuroshio Extension system and its impact on the wintertime SST field. J. Phys. Oceanogr., 30, 1486-1502.

Reynolds, R., 1978: Sea surface temperature anomalies in the North Pacific Ocean. Tellus, 30, 97-103.
Samelson, R., E. Skyllingstad, D. Chelton, S. Esbensen, L. O’Neill, and N. Thum, 2006: On the coupling of wind stress and sea surface temperature. J. Climate, 19, 1557-1566.

Saravanan, R., 1998: Atmospheric low-frequency variability and its relationship to midlatitude SST variability: Studies using the NCAR climate system model. J. Climate, 11, 1386-1404.

Schneider, N., A. Miller, and D. Pierce, 2002: Anatomy of North Pacific decadal variability. J. Climate, 15, 586-605.

Shin, S., P. Sardeshmukh, and K. Pegion, 2010: Realism of local and remote feedbacks on tropical sea surface temperatures in climate models. J. Geophys. Res., 115, D21110, doi:10.1029/ 2010JD013927.

Small, R., and Coauthors, 2008: Air-sea interaction over ocean fronts and eddies. Dyn. Atmos. Oceans, 45, 274-319.

Sura, P., and M. Newman, 2008: The impact of rapid wind variability upon air-sea thermal coupling. J. Climate, 21, 621-637.

$[,-\ldots$, and M. Alexander, 2006: Daily to decadal sea surface temperature variability driven by state-dependent stochastic heat fluxes. J. Phys. Oceanogr., 36, 1940-1958.

Sutton, R., and P. Mathieu, 2002: Response of the atmosphereocean mixed-layer system to anomalous heat-flux convergence. Quart. J. Roy. Meteor. Soc., 128, 1259-1275.

Taguchi, B., H. Nakamura, M. Nonaka, and S. Xie, 2009: Influences of the Kuroshio/Oyashio Extensions on air-sea heat exchanges and storm-track activity as revealed in regional atmospheric model simulations for the 2003/04 cold season. J. Climate, 22, 6536-6560.

,,,--- N. Komori, A. Kuwano-Yoshida, K. Takaya, and A. Goto, 2012: Seasonal evolutions of atmospheric response to decadal SST anomalies in the North Pacific subarctic frontal zone: Observations and a coupled model simulation. J. Climate, 25, 111-139.

Thompson, L., and Y. Kwon, 2010: An enhancement of lowfrequency variability in the Kuroshio-Oyashio Extension in CCSM3 owing to ocean model biases. J. Climate, 23, 6221-6233.

Winkler, C., M. Newman, and P. Sardeshmukh, 2001: A linear model of wintertime low-frequency variability. Part I: Formulation and forecast skill. J. Climate, 14, 4474-4494.

Xie, S., 2004: Satellite observations of cool ocean-atmosphere interaction. Bull. Amer. Meteor. Soc., 85, 195-208.

Yu, L., and R. Weller, 2007: Objectively analyzed air-sea heat fluxes for the global ice-free oceans (1981-2005). Bull. Amer. Meteor. Soc., 88, 527-539.

Yulaeva, E., N. Schneider, D. Pierce, and T. Barnett, 2001: Modeling of North Pacific climate variability forced by oceanic heat flux anomalies. J. Climate, 14, 4027-4046.

Zubarev, A., and P. Demchenko, 1992: Predictability of averaged global air temperature in a simple stochastic atmosphericocean interaction model. Izv. Atmos. Ocean. Phys., 28, 19-23. 